\title{
Maintaining the Public Trust in Journals with Ethical Publishing
}

\author{
Mark B. Mycyk ${ }^{1}$
}

Received: 26 October 2017 / Accepted: 26 October 2017 / Published online: 6 November 2017

(C) American College of Medical Toxicology 2017

Keywords Ethics $\cdot$ Publishing $\cdot$ Plagiarism $\cdot$ Scientific misconduct

As we are near the end of 2017 and complete our 13th continuous year of publishing here at Journal of Medical Toxicology (JMT), we should take this natural opportunity to pause, reflect, and look forward.

We are proud of the work we publish at JMT. We recognize most published papers are not perfect and not every issue is packed with prospective, randomized, blinded, and controlled studies, because it is unethical to poison patients prospectively and just watch what happens to them. We welcome all submission types, including clinical and bench research studies, review articles, retrospective studies, case series, and even welldetailed case reports that meaningfully add to the growing body of literature in medical toxicology. All manuscripts we publish undergo careful editorial and peer review, and before we publish a manuscript, we ask ourselves (i) if the topic, scope, and overall quality of a manuscript will likely lead to ongoing interest among academicians in medical toxicology or related fields, (ii) if the subject matter of the manuscript furthers the underlying basic or clinical science of medical toxicology or the practicing medical toxicologist, and most importantly, (iii) if the manuscript meets the ethical standards for the Journal of Medical Toxicology. As we come to the end of this year, we think it is important to remind our readers and authors of our commitment to publishing work that meets the highest ethical standards in biomedical publishing.

Mark B. Mycyk

mmycyk@cookcountyhhs.org

1900 West Polk Street, Chicago, IL 60091, USA
At $J M T$, we unconditionally endorse the best practice policies and ethical standards of the International Committee of Medical Journal Editors (ICMJE) for conducting and disseminating scholarly work in medical journals [1]. Our patients, the clinicians who treat them, and the policymakers involved in various aspects of healthcare rely on credible, honest scholarship to inform decision-making. We agree also with the Society of Academic Emergency Medicine's (SAEM) recently published position statement that "the integrity of the research enterprise is of the utmost importance for the advancement of safe and effective medical practice for patients and for maintaining the public trust in health care" [2].

Unfortunately, scientific misconduct that complicates our shared goal of providing the best possible care continues to happen in biomedical publishing. To date, we have been lucky at $J M T$, but letting something get published that does not meet our standard of ethical integrity can certainly happen here as has already occurred in most journals. According to some estimates, anywhere from 0.02 to $0.2 \%$ of published papers include some degree of fraudulent work or other misconduct [3] - that is, a staggering number when considering that over 28,000 journals publish over 2,000,000 new articles each year.

So, how do we define misconduct in scholarship? The United States Office of Research Integrity (ORI) provides the most consistently referenced guidance with their definition of misconduct as "fabrication, falsification, or plagiarism in proposing, performing, or reviewing research, or in reporting research results." [4]. Fabrication of data or distortion of findings are obvious breaches of ethical scientific conduct that can have long-lasting negative effects as exemplified by the retracted paper of Andrew Wakefield on vaccines and autism [5]. According to a sobering meta-analysis published almost 10 years ago, almost $2 \%$ of published scientists "admitted to have fabricated, falsified or modified data or results at least once - a serious form of misconduct by any standard - and up 
to $33.7 \%$ admitted other questionable research practices." [3]. This is why all submissions to $J M T$ are subjected to careful review by experienced editors and content experts, and when numbers are used in a manuscript, we also rely on the talented eye of a statistical editor.

The responsibility for ensuring that misconduct does not reach the bedside of a patient is a collective one [1]. Of course, authors need to be honest and meticulous with their work as recommended by the ICMJE as the first and most important safeguard; then, editors and reviewers are entrusted with evaluating all aspects of a submission carefully; then, readers of journals should apply their own experience and perspective to assess published papers and voice their concerns in journal clubs, with letters to the editor, and through their own scholarship to correct what they sense might not smell right.

Earlier this year, we were fortunate to publish a terrific Proceedings paper by Dr. Jeremy Sugarman and Dr. Andrew Stolbach, both at Johns Hopkins, from a talk about the ethics of toxicology research delivered at ACMT's 2017 Annual Scientific Meeting [6]. The guidance in the Proceedings is mostly intuitive and common sense, but hearing the talk in person and then reading it on paper reinforced for me the principles we all know should always be followed. Sugarman is absolutely correct in asserting that "optimizing care in medical toxicology necessitates designing and conducting ethical research" [6]. And we would like to emphasize that dissemination of that research and dissemination of all other forms of scholarship similarly needs to be done ethically.

Sometimes, errors in studies are honest mistakes that happen unintentionally, and those mistakes then get incorporated into a manuscript submission. Our review process identifies such errors and allows authors to fix correctable problems before a manuscript gets published. Yes, our review process is sometimes tough because our reviewers ask good questions, we require signed conflict of interest (COI) forms and explicit disclosure of IRB oversight or subject consent, but that is all done to ensure that the best possible work is published so no one looks back with regret years later.

However, when misconduct is committed intentionally for whatever gain, we all have an obligation to recognize it and do something about it even though there is no clear guidance or policies on how to do that $[1,7]$. When honest mistakes happen, they are forgivable and we can publish an erratum when discovered. Dealing with intentional misconduct is far more complicated. In recent years, the website Retraction Watch and other news media have helped investigate misconduct to assist editors in publishing an erratum or retracting a paper when authors were unwilling to cooperate with inquiries as in the case of the Wakefield study [8]. One would think that the harsh attention given to scientific misconduct by news media would serve to deter it, but it seems misconduct has gotten worse because "the number of articles retracted per year increased by a factor of 19.06 from 2001 to 2010" [9]. When adjusted for repeat offenders, the factor was closer to 11 [9].

Finally, it is important to bring up the issue of plagiarism, because in many ways, it is more complicated to detect, investigate, and correct. Unlike the other forms of misconduct defined by the U.S. Office of Research Integrity, plagiarism does not distort scientific knowledge as much as it has important consequences for the careers of scholars and thus for the whole scientific enterprise [3, 10]. Earlier this year, the editor-in-chief of Annals of Internal Medicine reported that the reviewer of one of its manuscripts "had stolen the contents of a manuscript sent to that reviewer for evaluation" and then that reviewer published that very same content almost verbatim in another journal [11]. Although that is obviously an egregious and bold form of plagiarism, in today's world of electronically shared and distributed data, plagiarism runs the entire gamut from overt plagiarism of another's intellectual property (as in that Annals case) to patchwork plagiarism from various sources, including from oneself [2]. Regardless of how it happens, any form "plagiarism tarnishes the research integrity" [12]. Why does it happen? Some reasons include a lack of formal training in ethical writing, poor oversight by senior authors, plain ignorance, and the ubiquitous use of electronically available information that make copy/paste easy and the boundaries of what is original and what is plagiarism blurry for younger scholars who are facile with social media (e.g., Twitter) and FOAMed (Free Open Access Medical Education) [12]. At $J M T$, we rely on several levels of experienced eyes, and like other journals, we have adopted the use of plagiarism detection software that has actually prevented a few submissions from getting past the decision editor's desk. $J M T$ also belongs to the UK-based Committee on Publication Ethics (COPE), a multidisciplinary organization with a goal of improving the ethical practices of all forms of scholarship [7]. COPE's Code of Conduct document provides us with guidance about a wide range of increasingly complex ethical issues in journal publishing [7]. Some journal editors have discouragingly concluded, "regrettably, predicting plagiarism is impossible, and its appropriate management continues to be problematic...we can't stop it; we can only hope to contain it." [11]. At JMT, we prefer an optimistic view by openly reminding authors and readers of our principles and leading by example.

We do not publish the most manuscripts, but we try to be careful by adhering to a high standard. We do not cut corners. We do not game the system to improve our citations, our impact, or the careers of select individuals. We require submitted conflict of interest (COI) statements from all authors, we require disclosure of IRB and consent procedures to be clear, we have a policy for appealing decisions, and we have a letters to the editor section called the Poison Pen that allows readers to speak up. Our aspiration is a shared responsibility 
among all stakeholders to allow honest ethical work to reach readers and impact patient care in the best possible way. Only then can we maintain the public trust in this journal and all journals that inform and advance health care.

\section{Compliance with Ethical Standards}

\section{Conflicts of Interest None}

Additional Disclosure Mark B. Mycyk, MD is the editor-in-chief of Journal of Medical Toxicology (JMT).

\section{References}

1. International Committee of Medical Journal Editors. Recommendations for the conduct, reporting, editing, and publication of scholarly work in medical journals. 2016. Available at: http://www.icmje.org/icmje-recommendations.pdf. Accessed 24 October 2017.

2. Asher SL, Iserson KV, Merck LH. Society of Academic Emergency Medicine statement on plagiarism. Acad Emerg Med. 2017;24(10): $1290-2$.
3. Fanelli D. How many scientists fabricate and falsify research? A systematic review and meta-analysis of survey data. PLoS One. 2009;4(5):e5738.

4. The United States Office of Research Integrity (ORI). https://ori. hhs.gov/handling-misconduct. Accessed 24 October 2017.

5. Wakefield AJ, Murch SH, Anthony A, Linnell J, et al. Illeallymphoid-nodular hyperplasia non-specific colitis, and pervasive developmental disorder in children. Lancet. 1998;351:637-41.

6. Sugarman J, Stolbach A. Ethics and medical toxicology research. J Med Toxicol. 2017;13(3):255-8.

7. Committee on Publication Ethics (COPE). https://publicationethics. org/files/Code_of_conduct_for_journal_editors_Mar11.pdf. Accessed 24 October 2017.

8. http://retractionwatch.com. Accessed 24 October 2017.

9. Grieneisen ML, Zhang M. A comprehensive survey of retracted articles from the scholarly literature. PLoS One. 2012;7(10):e44118.

10. Steneck NH. Fostering integrity in research: definitions, current knowledge, and future directions. Sci Eng Ethics. 2006;12:53-74.

11. Fred HL, Scheid MS. Egregious plagiarism: more than misconduct. Tex Heart Inst J. 2017;44(1):7-8.

12. Juyal D, Thawani V, Thaledi S. Plagiarism: an egregious form of misconduct. N Am J Med Sci 2015;7(2):77-80. 